\title{
Factors Associated with Tuberclosis-HIV Co-Infection in Diagnosis in the Nzanza Health Zone
}

\author{
Carine Nkembi Nzuzi1,2,3, Marie Onyamboko² ${ }^{2}$ Jacques Kokolomami², Herve Alex Tukadila ${ }^{3}$, \\ Aliocha Nkodila Natuhoyila ${ }^{3 *}$, Benjamin Longo-Mbenza ${ }^{3,4,5}$
}

${ }^{1}$ Faculty of Medicine, Kasa-Vubu University, Boma, Democratic Republic of Congo

${ }^{2}$ School of Public Health, Faculty of Medicine, Kinshasa, Democratic Republic of Congo

${ }^{3}$ Faculty of Public Health, Lomo University of Research, Kinshasa, Democratic Republic of Congo

${ }^{4}$ Department of Internal Medicine, University of Kinshasa, Kinshasa, Democratic Republic of Congo

${ }^{5}$ Faculty of Health Sciences, Walter Sisulu University, Mthatha, South Africa

Email: *nkodilaaliocha@gmail.com

How to cite this paper: Nzuzi, C.N., Onyamboko, M., Kokolomami, J., Tukadila, H.A., Natuhoyila, A.N. and Longo-Mbenza, B. (2021) Factors Associated with TuberclosisHIV Co-Infection in Diagnosis in the Nzanza Health Zone. Open Access Library Journal, 8: e7105.

https://doi.org/10.4236/oalib.1107105

Received: December 22, 2020

Accepted: March 14, 2021

Published: March 17, 2021

Copyright $\odot 2021$ by author(s) and Open Access Library Inc.

This work is licensed under the Creative Commons Attribution International License (CC BY 4.0).

http://creativecommons.org/licenses/by/4.0/

\begin{abstract}
Aim: To determine the factors associated with the increase in the proportion of HIV-infected TB patients of Kiamvu and Baobab Tuberculosis Screening and Treatment Health Center (TSTHC) in the Nzanza HZ, Matadi, between January 2012 and December 2017. Methods: This was a control case study of 187 HIV-positive TB patients and $187 \mathrm{HIV}$-negative TB patients followed at the Nzanza HZ Tuberculosis Screening and Treatment Health Center (TSTHC) from January 1, 2012 to December 31, 2017. We used Pearson's Khi square test and homogeneity as well as logistic regression. This identified the factors associated with TB/HIV co-infection. Results: HIV-positive TB patients had a high daily household income [OR: 2.90; p. 0.000]) than HIV-negative people. The majority of HIV-positive TB patients had unprotected sex with a casual partner prior to diagnosis [OR: 1.82; $p: 0.000]$ ] than HIV-negative. After adjustment, alcohol intake [OR: $12.2 ; p: 0.004]$ ) and extra pulmonary forms of tuberculosis [OR: 31.5 ; 0.002] were associated with increased TB/HIV co-infection. Conclusion: Alcohol intake and extra-pulmonary forms of tuberculosis were factors associated with increased TB/HIV co-infection. Awareness of TB patients may help reduce the risk of HIV infection.
\end{abstract}

\section{Subject Areas}

Infectious Diseases

\section{Keywords}

HIV infection, Factors Associated, Tuberclosis, Nzanza Health Zone 


\section{Introduction}

Human immunodeficiency virus (HIV) infection is a major burden in some countries around the world but especially in resource-limited countries in sub-Saharan Africa [1]. This infection is due to the human immunodeficiency virus, belonging to the lentivirus subgroup. Currently there are two serotypes; HIV 1 has spread to the world and HIV 2 is found in West Africa [2]. Between 2000 and 2016, the number of new HIV infections decreased by $39 \%$ and the number of HIV-related deaths fell by a third with 13.1 million lives saved. At the end of 2015, there were approximately 1.1 million adults and children who died of AIDS worldwide, 800,000 of whom lived in sub-Saharan Africa [3].

This region of Africa has about 25.6 million people living with HIV (HIV), including 2.3 million children under the age of 15 , or nearly $90 \%$ of the global burden of HIV/AIDS among children. The overall prevalence of HIV/AIDS in this region in 2015 was about $4.8 \%$, but rates vary widely from country to country, ranging from $5.3 \%$ in Kenya to $27.7 \%$ in Swaziland. It recorded 1.37 million opportunistic infections out of the 2.1 million new infections identified (65\% of the total) [4].

Awareness, testing and antiretroviral treatment have reduced this prevalence in many countries around the world, extending the lifespan of people living with HIV [2].

The Democratic Republic of Congo (DRC) is not immune to this AIDS pandemic. In 2016, HIV prevalence was $1.2 \%$ in the general population and $1.8 \%$ among pregnant women nationally. This prevalence has remained relatively stable since 2007, as a result of the efforts of the National HIV Programme for the management of HIV infection and community involvement in voluntary testing [5], despite the high prevalence in some border countries; Zambia (12.9\%), Uganda (7.1\%) Tanzania (4.7\%) [3]. In 2017, this prevalence was estimated at $1.1 \%$ in Central Kongo Province [6]. Several factors contribute to a high frequency of mortality linked to HIV-Tuberculosis co-infection. These include late detection and diagnosis, opportunistic infections (IOs) including tuberculosis in low- and intermediate-resource countries, and through cardiovascular disease, viral hepatitis and cancers in the industrialized country [7].

Tuberculosis (TB) is one of the most common opportunistic infections and the leading cause of preventable death in people living with HIV [8].

In 2015, there were an estimated 10.4 million new TB cases worldwide and its incidence decreased by $1.5 \%$ between 2014 and 2015 as a result of major advances in care and prevention. To achieve an annual reduction of $4 \%$ to $5 \%$ by 2020 , WHO proposes to accelerate this trend of management. But the strategy, which aims to end TB by 2035, believes that TB deaths should be reduced by $95 \%$ and the incidence of TB by $90 \%$ compared to 2015 [9] [10].

TB/HIV co-infection is comorbidity associating with the human immunodeficiency virus with the Koch TB bacillus. This HIV infection promotes the transition from latent TB to active TB in individuals. Tuberculosis can occur during 
HIV infection while immunodepression is not necessarily severe. When it occurs at an advanced stage of the disease, it may be one of the manifestations of the immune reconstruction syndrome (inflammatory syndrome: IRIS) observed in the aftermath of the implementation of highly active antiretroviral therapy (HAART) [11]. Co-infection is a major public health problem, especially in the low-resource (developing) country such as the Democratic Republic of Congo, with an estimated prevalence of $20 \%$ among TB/HIV co-infected people in 2016. [12].

In countries with high HIV prevalence, the number of new TB cases has tripled in the past two decades [13]. Among people living with HIV, at least one in four deaths is attributed to tuberculosis, the majority of which are in low-resource countries [14]. Therefore, we say that the impact of TB remains a concern. According to the WHO's 2016 annual TB control report, an estimated 10.4 million new TB cases, including 1.2 million living with HIV [9].

In Africa, HIV is the main determinant of the increase in TB incidence over the past decade. It has been estimated that people living with HIV are 20 to 37 times more likely to develop TB than the rest of the population [11]. Approximately $71 \%$ of cases of disease and 0.4 million TB deaths among people living with HIV have occurred in sub-Saharan Africa [9].

In this African Region, $81 \%$ of reported TB patients were positive for HIV [15]. Nevertheless, this proportion varies in the 28 African countries out of a total of 41 heavily affected by TB/HIV co-infection, ranging from 10\% in Angola and Ethiopia to $70 \%$ in Lesotho and Swaziland [16]. The proportion of TB patients while HIV-positive and on antiretroviral therapy was 45\% in 2015 in South Africa and over 90\% in Kenya, Malawi, Mozambique, Namibia and Swaziland [17]. Causes of death in patients co-infected with TB/HIV may vary depending on the severity of immunosuppression, timing of diagnosis, availability of rapid TB management and antiretroviral treatment [14].

The Democratic Republic of Congo is among the 30 countries most affected by tuberculosis, TB/HIV co-infection and multi-drug-resistant tuberculosis [18]. It is one of 28 African countries out of a total of 41 heavily affected by TB/HIV tailoring with a proportion of reported cases on antiretroviral treatment ranging from $48 \%$ to $67 \%$ [19].

Central Kongo Province is one of 26 provinces in the DRC. It borders Angola, which has an HIV prevalence of $2 \%$ in 2017 and whose cross-border movement of people is intense [20]. As a result, the majority of people infected with HIV in Angola come to the province for appropriate care. The incidence of TB/HIV co-infection at the provincial level has decreased by about $2 \%$ over the past 5 years; it rose from 14\% in 2011 to $12 \%$ in 2016 [21].

The city of Matadi, which is a port city and where traffic is very important, also sees its impact decrease during the last 5 years by about $3 \%$. Despite the interventions of the National Tuberculosis Program and the National Program to Combat HIV/AIDS, which have resulted in the decrease in the incidence of 
TB/HIV co-infection over the past 5 years at the provincial and city level of Matadi, NZANZA's health zone, located in Matadi and whose population movement is intense with high promiscuity, has seen its incidence gradually increase, from 6\% in 2011 to $10 \%$ in 2016 in the 2 TSTHC (GHR Kiamvu and Baobab) while it has decreased in the other TSTHC in the city of Matadi and central Kongo Province [21].

Tuberculosis is a bacterial disease caused by Mycobacteruim tuberculosis corresponding to different germs mainly Koch bacillus or KB, promoted by several factors including HIV infection and poverty. It reaches the labour force between the ages of 15 and 49 and is one of the most fatal communicable diseases in the world. To reduce the burden of TB associated with HIV, HIV testing in TB is the first intervention, followed by ART and Isoniazide treatment [22].

Tuberculosis services are therefore an important entry point for the diagnosis and care of HIV infection. They can also be used to manage both diseases simultaneously, at least for the duration of TB treatment [23].

$\mathrm{TB} / \mathrm{HIV}$ co-infection is a burden on the health system of countries around the world in general and in Africa in particular with significant diagnostic and therapeutic challenges [24]. Globally in 2016, 57\% of reported TB patients tested positive for HIV, up slightly from $55 \%$ in 2015 and multiplied by 19 times since 2004. In the WHO African Region, where the burden of HIV associated with TB is highest, $82 \%$ of TB patients tested positive for HIV and $85 \%$ were on antiretroviral therapy (ART) [25] compared to 78\% in 2015 [16].

HIV surveillance in TB patients remains an important activity as TB is fuelled by the HIV epidemic and especially since the majority of TB patients are unaware of their HIV status [26]. Further progress has been made in the implementation of joint TB and HIV activities, the interim version of which was published in 2004 and updated in 2012 by WHO. These have provided early access to HIV diagnosis, ART and increased survival of HIV-infected TB patients, improving TB treatment outcomes [23].

Thiago Nascimento et al. in Brazil, had found that the prevalence of TB/HIV co-infection was 19\% between 1 January 2007 and 31 December 2011; and Arun Mohan M. V et al. in southern India from November 1, 2010 to December 30, 2011. For these studies, the male sex, the age range ranging from 20 to 49 years, the low level of education were mentioned as factors that increase the case of TB/HIV co-infection. The India study added the low socio-economic level, while Brazil's had talked about failure of treatment and the combination of pulmonary and extra-pulmonary tuberculosis [27] [28].

Musafiri and Al. Kisangani in 2010 and Akilimali PZ et al. in Kinshasa Cabinda in 2013, identified that the majority of co-infected patients were female [29] [30]. Yihun Mulugeta Alemu and Al. in 2014 in Ethiopia, had cited tobacco and alcohol as factors that increase the risk of TB among people infected with HIV in Ethiopia [31].

Akilimali and Al. in a study conducted in Matadi, DRC in 2009, found that 
the prognosis for TB treatment in HIV-infected patients was less favourable than that of HIV-negative subjects [32]. Musafiri and Al. in Kisangani in 2010, had identified relapse with TB treatment as a risk factor in the majority of TPM patients with HIV seroprevalence [29].

Batista and Al. in a study conducted in Brazil between 2007 and 2010, found that CD4 levels below 200 increased the risk of co-infection in PHAs [33]. Yone et al., in a study conducted in Cameroon (Yaounde) in 2009 and Akilimali and Al. in Cabinda (Kinshasa) between 2010 and 2013, reported that HIV infection is common in TB patients with negative and extra pulmonary tuberculosis than non-co-opted people. This infection was associated with excess mortality in severe immune deficiency, despite antiretroviral treatment and cotrimoxazole prophylaxis [30] [34].

E. Goluba and Al. in South Africa, had found that treatment with isoniazide allows a significant reduction in TB rates of $89 \%$ in PVVs after active treatment with ART [35] Fiogbé AA and Al. In a 2011 study conducted in northwest Benin, followed at the screening and treatment center, found that mortality was high in TB/HIV co-infected patients, the majority of whom had CD4-200 [24] levels.

However, two control case studies were conducted in a hospital setting in Addis Ababa, Ethiopia. One by Kelemu Tilahun Kibret and al. December 2011 to February 2012 and the other by Yihun Mulugeta Alemu and al. June 1 to June 5, 2014. These studies have shown that isoniazide prophylaxis, cotrimoxasole and highly active antiretroviral therapy (HAART) have a protective effect against Tub/HIV co-infections in Ethiopia [31] [36]. In our context, we believe that promiscuity, poverty (low household income) and behaviours at risk of certain TB patients, such as the notion of multiple partner, exchange of contaminated tools or materials, unsuscitated sexual relationship protected with an occasional partner would increase cases of co-infection. In addition, we noted the lack of information or data on the factors that underscored the increase in cases of co-infection in Nzanza since 2013.

\section{Material and Methods}

It covers the period from January 1, 2012 to December 31, 2017 and the collection of data from February 10 to March 5, 2018. This study was carried out in the city of Matadi, in the THTC of GHR Kiamvu and Baobab, HZ of Nzanza. This research will include two components: A trend study that used the programmatic data produced by the National AIDS Programme and the National Tuberculosis Programme to assess the trend of annual proportions of coinfection in the two study Tuberculosis Screening and Treatment Health Center (TSTHC). A study of the associated factors: This component consists of a case-control study, including: Case: Any person aged 18 and over, HIV-infected TB patients who were consulted and managed in GHR Kiamvu and Baobab TSTHC during the study period. Witnesses: any HIV-infected TB patients aged 
18 and over, consulted and cared for in GHR Kiamvu and Baobab TSTHC during the study period, matched to cases based on age plus or minus two years, sex, months of diagnosis and living environment.

The sampling will be simple random probability. The size of the sample will be calculated by Keyes' formula: $n \geq \frac{2\left(Z_{\alpha}+Z_{1-\beta}\right)^{2} \times P(1-P)}{\left(P_{0}-P_{1}\right)^{2}} \quad Z_{1-\alpha}=Z_{0.995}=1.65$. One-sided test (the confidence coefficient at the significance level $=0.05$ ), $Z_{1-\beta}=Z_{1-0.80}=Z_{0.80}=0.83$ : the detection capacity per test, of the significant difference $(\mathrm{u}=80 \%)$.

$P_{0}$ : The expected proportion of HIV among cases is $20 \%(0.20)$.

OR: the odds ratio is $=2.0$.

$P_{1}$ : the expected proportion of HIV in the general population.

$P$ : the proportion of those exposed to the risk factor in the two groups (case and control)

$$
\begin{gathered}
P_{1}=\frac{\left(P_{0} \times \mathrm{OR}\right)}{1+P_{0}(\mathrm{OR}-1)}=\frac{(0.20 \times 2)}{1+0.2(2-1)}=0.333 \\
P=\frac{\left(P_{0}+P_{1}\right)}{2}=\frac{(0.2+0.33)}{2}=0.27 \\
n \geq \frac{2(1.65+0.83)^{2} \times 0.27(1-0.27)}{(0.20-0.33)^{2}}=143 \text { subjects. }
\end{gathered}
$$

We increased the sample size to 187 PLHIV for the power of the test. As a case-control study, 187 non-PLHIV were also included by matching.

To collect the data, we conducted: A documentary review that provided access to the records and records of co-managed and uncomviewed tuberculosis in the Kiamvu and Baobab TSTHC, this task was completed by the research team and took 5 days. Direct interview or interview using a structured questionnaire that was administered to cases and witnesses by investigators after obtaining informed and written consent of the subject.

\section{Statistical Analyzes}

The collected data was captured and codified using the EPIDATA version 3.1 software and analyzed using the SPSS software version 23 (Statistical Package for the Social Science). During the analysis, data monitoring and cleaning were carried out to detect missing, incomplete and inconsistent data. The production of the paintings by Excel 2010. The calculation of central trend measures including the average and the standard deviation to express quantitative variables and frequency measurements including the ratio to express categorical variables. We used Pearson's Chi Square test for dichotomy variable and homogeneity Chi Square for variables with more than two modalities to establish a relationship or association between TB/HIV co-infection and different independent variables. As a measure of association, the Ratios (OR) report estimated the association 
strength with its confidence interval at $95 \%$ and a $\mathrm{p}$ less than 0.05 . The logistic regression model identified the factors associated with the increase in co-infection cases in the Nzanza HZ.

\section{Ethical Considerations}

During this study, the three main ethical principles were respected, including respect for the human person, charity and the principle of justice. In relation to respect for the human person, informed consent was obtained from all study participants and confidentiality was guaranteed. From a charitable point of view, the risk/benefit balance was explained to them. Regarding justice, explain to respondents that the benefits and risks associated with the study will be fairly assumed and redistributed and assuring them the enjoyment of the benefits that will be provided by the study.

\section{Results}

The different results obtained during the study of HIV-infected TB patients from the TSTHC in the Nzanza Health Zone, Matadi City, Kongo-Central from January 01, 2012 to December 31, 2017. These results are grouped into a table taking into account the following: Determining the proportions of TB patients co-infected with HIV and not in the GHR Kiamvu TSTHC and the Baobab TSTHC of the Nzanza Health Zone; The socio-demographic characteristics of the respondents in the Nzanza HZ; Factors associated with the increase in HIV infections in Kiamvu and Baobab TSTHC TB patients during the study period; Regarding the origin of the respondents, the difference was significant ( $p=$ 0.017 ) in cases and controls in the TSTHC Baobab than in the Kiamvu TSTHC. There was no difference from the municipalities of origin $(p=0.059)$ (Table 1$)$.

On the subject of socio-demographic characteristics, there was no difference in age $(p=0.802)$. The sexes were evenly distributed in both groups $(p=1.000)$. There was no difference between the two groups from the level of study ( $p=$ $0.093)$ and marital status $(p=0.716)$. From the point of view of the occupancy of cases and controls the difference was significant among traders $(p=0.017)$ (Table 2).

From the typical household perspective, the majority of cases had an income of at least $\$ 1.25 /$ person/day than the controls; the difference was significant ( $p=$ 0.000). There was no difference between the two groups in terms of number of people per household $(p=0.096)$ and alcohol consumption $(p=0.196)$. There was a significant difference between cases and controls for unprotected sex with casual partners $(p=0.003)$. The difference was statistically significant between cases and controls for the form of extra pulmonary tuberculosis $(p=0.000)$ (Table 3).

After adjustment, alcohol intake $(p=0.004)$ and forms of extra-pulmonary tuberculosis $(p=0.002)$ appeared to be associated with TB/HIV co-infection in the Nzanza HZ (Table 4). 
Table 1. Breakdown of respondents according to some characteristics of individuals and households.

\begin{tabular}{|c|c|c|c|c|c|c|}
\hline Characteristics & & Effective & $\%$ & Effective & $\%$ & $p$ \\
\hline Provenance & & Cases $(\mathrm{n}=187)$ & & Witnesses $(\mathrm{n}=187)$ & & \\
\hline \multirow{2}{*}{ CSDT } & Kiamvu & 137 & 73.3 & 156 & 83.4 & \multirow{2}{*}{0.017} \\
\hline & Baobab & 50 & 26.7 & 31 & 16.6 & \\
\hline \multirow{3}{*}{ Commune from } & Matadi & 4 & 2.1 & 4 & 2.1 & \multirow{3}{*}{0.059} \\
\hline & Mvuzi & 23 & 12.3 & 23 & 12.3 & \\
\hline & Nzanza & 160 & 85.6 & 160 & 85.6 & \\
\hline
\end{tabular}

Table 2. Breakdown of respondents by some sociodemographic characteristics.

\begin{tabular}{|c|c|c|c|}
\hline Variable & $\begin{array}{c}\text { Cases } \\
(n=187)\end{array}$ & $\begin{array}{l}\text { Witnesses } \\
(n=187)\end{array}$ & $p$ \\
\hline Age (years) & & & 0.802 \\
\hline$<20$ & $15(8.0)$ & $14(7.5)$ & \\
\hline $20-29$ & $16(8.6)$ & $14(7.5)$ & \\
\hline $30-39$ & $51(27.3)$ & $46(24.6)$ & \\
\hline $40-49$ & $48(25.7)$ & $59(31.6)$ & \\
\hline$\geq 50$ & $57(30.5)$ & $54(28.9)$ & \\
\hline Sex & & & 1.000 \\
\hline Male & $82(43.9)$ & $82(43.9)$ & \\
\hline Female & $105(56.1)$ & $105(56.1)$ & \\
\hline Study level & & & 0.093 \\
\hline None & $13(7.0)$ & $14(7.5)$ & \\
\hline Primary & $47(25.1)$ & $46(24.9)$ & \\
\hline Secondary & $89(47.6)$ & $106(56.7)$ & \\
\hline University & $38(20.3)$ & $21(11.3)$ & \\
\hline \multicolumn{4}{|l|}{ Marital status } \\
\hline Single & $79(42.2)$ & $71(38.0)$ & \\
\hline Married & $63(33.7)$ & $73(39.0)$ & \\
\hline Divorced & $14(7.5)$ & $15(8.0)$ & 0.716 \\
\hline Widow(er) & $20(10.7)$ & $21(11.2)$ & \\
\hline De facto union & $11(5.9)$ & $7(3.7)$ & \\
\hline Occupation & & & 0.017 \\
\hline Without Occupation & $80(42.8)$ & $92(49.2)$ & \\
\hline State Employe & $20(10.7)$ & $9(10.2)$ & \\
\hline Private Worker & $32(17.1)$ & $37(19.8)$ & \\
\hline Trader & $24(12.8)$ & $13(7.0)$ & \\
\hline Farmer & $7(3.7)$ & $16(8.6)$ & \\
\hline Other & $24(12.8)$ & $10(5.3)$ & \\
\hline
\end{tabular}


Table 3. Breakdown of respondents based on some household characteristics, risk behavior and forms of tuberculosis.

\begin{tabular}{|c|c|c|c|}
\hline Characteristics & $\begin{array}{c}\text { Cases } \\
(n=187)\end{array}$ & $\begin{array}{l}\text { Witnesses } \\
(n=187)\end{array}$ & $p$ \\
\hline \multicolumn{4}{|l|}{ Household Characteristics } \\
\hline Household income & & & $<0.001$ \\
\hline Less than $\$ 1.25 /$ person/day & $122(43.6)$ & $158(56.4)$ & \\
\hline At least $\$ 1.25 /$ person/day & $65(69.1)$ & $29(30.9)$ & \\
\hline Number of persons per household & & & 0.096 \\
\hline$\geq 5.7$ & $96(46.2)$ & $112(53.8)$ & \\
\hline$<5.7$ & $91(54.8)$ & $75(45.8)$ & \\
\hline Risky Behavior adopted by TB & & & 0.196 \\
\hline \multicolumn{4}{|l|}{ Alcohol } \\
\hline Yes & $74(39.6)$ & $65(34.8)$ & \\
\hline No & $113(60.4)$ & $122(65.2)$ & \\
\hline Unprotected sexual relationship with casual partner & & & 0.003 \\
\hline Yes & $123(65.8)$ & $96(51.3)$ & \\
\hline No & $64(34.2)$ & $91(48.7)$ & \\
\hline \multicolumn{4}{|l|}{ Factors Related to Tuberculosis Pulmonary } \\
\hline Tuberculosis Forms & & & $<0.001$ \\
\hline Pulmonary & $127(67.9)$ & $165(88.2)$ & \\
\hline Extra Pulmonary & $60(32.1)$ & $22(11.8)$ & \\
\hline
\end{tabular}

Table 4. Factors associated with TB/HIV Co-infection.

\begin{tabular}{|c|c|c|c|c|}
\hline Variables & $\begin{array}{l}\text { Unadjusted OR } \\
(95 \% \mathrm{CI})\end{array}$ & $p$ & $\begin{array}{c}\text { Adjusted OR } \\
(95 \% \mathrm{CI})\end{array}$ & $p$ \\
\hline \multicolumn{5}{|l|}{ Marital status } \\
\hline Married & 1 & & 1 & \\
\hline Unmarried & $1.14(0.756-1.724)$ & 0.599 & $0.80(0.22-2.88)$ & 0.737 \\
\hline \multicolumn{5}{|l|}{ Education level } \\
\hline Low & 1 & & 1 & \\
\hline High & $1.00(0.648-1.544)$ & 0.168 & $0.41(0.09-1.59)$ & 0.126 \\
\hline \multicolumn{5}{|l|}{ occupation } \\
\hline Unemployed & 1 & & 1 & \\
\hline With employment & $0.77(0.514-1.161)$ & 0.254 & $1.67(0.17-16.49)$ & 0.655 \\
\hline \multicolumn{5}{|l|}{ Household income } \\
\hline Less than $\$ 1.25 /$ person/day & 1 & & & \\
\hline At least $\$ 1.25 /$ person/day & $2.90(1.765-4.773)$ & 0.001 & $1.1(0.276-4.161)$ & 0.920 \\
\hline \multicolumn{5}{|l|}{ Alcohol } \\
\hline No & 1 & & 1 & \\
\hline Yes & $12.3(1.808-18.69)$ & 0.001 & $12.2(2.2-66.8)$ & 0.004 \\
\hline
\end{tabular}




\section{Continued}

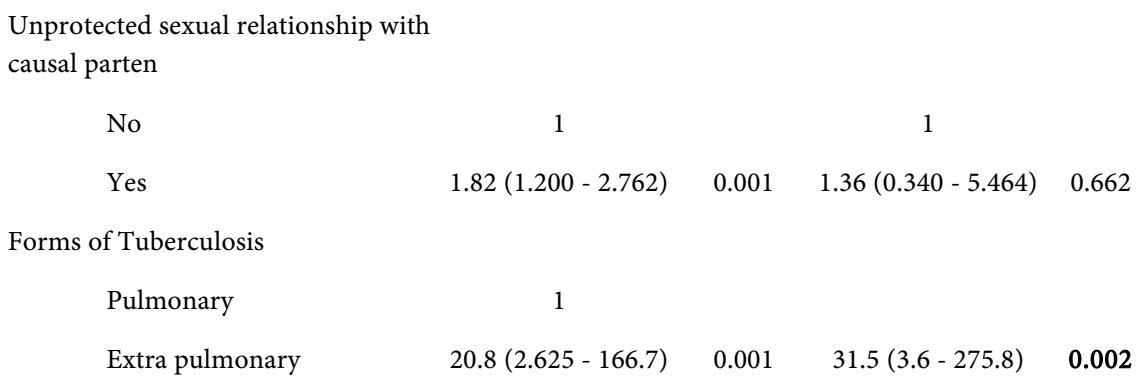

\section{Discussion}

The question before starting this study was what the factors are associated with the increase in TB-HIV co infections in the Nzanza health zone in Matadi. After this study, the main results found showed that alcohol intake and extra pulmonary form were factors associated with the increase in HIV in Nzanza TB patients. Kiamvu TSTHC reported many more cases and controls, and TB/HIV co-infection was predominant in Nzanza commune than in other municipalities in the city. From a socio-demographic point of view, age was the same among TB/HIV co-infected and no, this is not consistent with the study by P. Akilimali et al. Kabinda DRC, which shows that co-infected TB patients were older than non-co-infected TB [30]. Our results are different from those in the literature because we matched a case for a witness based on age plus or minus two. In this study, the female prevalence among co-infected TB patients is consistent with the feminization of HIV infection in the general population. This means that in our study, women with TB were four times more likely to be HIV-positive than men. This is consistent with the 2013-2014 demographic survey conducted in the DRC, where HIV prevalence was higher among women [5]. The majority of co-infected in our study were single, as it is singles who are looking for sexual performance and adopting a different lifestyle. This corroborates Mohan M.V.'s study, and al. [27]. Co-infected TB patients had a daily income of at least $\$ 1.25$ per person per day, compared to non-co-infected TB. We think this is related to their daily activities that exposed them. This is consistent with Magadi M's study for sub-Saharan Africa [37] [38], which shows that higher socio-economic status of households was a higher risk factor for HIV transmission. But a study done in Kisangani (DRC) by Musafiri and Al. have shown that poverty is among the factors that increase the risk of transmission and the vulnerability of HIV infection in the community [29] [39]. When it came to alcohol intake, HIV-infected TB patients were drinking more alcohol than non-co-infected TB patients. Patients exposed to alcohol were 12 times more likely to be co-infected than non-alcoholic. Alcohol being a psychoactive substance, can lead to abuse and loss of the person's freedom of action. Our results corroborate with that of Kelemu Tilahun Kibret et al. in Ethiopia, where HIV-infected TB patients were twice as exposed as non-co-infected people [36]. A review of the literature dating back to 2010 for a prospective study showed a strong association between the in- 
cidence of HIV infection and alcohol consumption, it showed that individuals who consume alcohol have a $77 \%$ risk of HIV infection that those who do not use it, those who use it before or during sexual intercourse have an $87 \%$ increased risk, and those who take large amounts in a short period of time have a double risk compared to those who do not [40]. Extra pulmonary forms of TB were found more in HIV-infected TB patients than non-co-infected TB patients. Extra pulmonary tuberculosis occurred 32 times more in HIV-infected TB patients than non-co-infected TB. Likewise P. Akilimali et al. showed that HIV-positive TB patients in the DRC (Kabinda) had more extra-pulmonary forms and smear-negative pulmonary tuberculosis [30]. It has been shown that the more advanced patients are immunodepression, the more forms of extra-pulmonary tuberculosis they have and the less cavitary forms of pulmonary tuberculosis.

\section{Conclusion}

Our study aimed to shed awareness of the associated factors of TB/HIV co-infection in the Nzanza HZ. HIV-infected TB patients are comparable to non-co-infected with HIV on certain socio-demographic characteristics. In terms of behavior the alcohol intake was probably due to the search for performance and the need to forget problems. The extra pulmonary form of tuberculosis appears to be linked to strong immunodepression. Awareness of TB patients may help reduce the risk of HIV infection. In view of the high rate of co-infection, it is necessary to reduce alcohol intake and better care for PLWHIV.

\section{Acknowledgements}

The authors would like to thank the staff members of the study formations for their cooperation during data collection. They are also grateful to the Laboratory staff and to the PLWHIV followed in these training courses.

\section{Authors' Contribution}

NNC designed the study. NNA, TLHA participated in statistical data analysis, $\mathrm{OM}, \mathrm{KJ}$ participated in data design and acquisition; LMB supervised the study. All authors contributed to the drafting of the document and approved the final document.

\section{Conflicts of Interest}

The authors declare no conflict of interest

\section{References}

[1] Joint United Nations Programme on HIV/AIDS (2014) Un rapport de la situation mondial sur le VIH', Communique de Presse. Joint United Nations Programme on HIV/AIDS, Geneve, 1 
[2] Desenclos, J.-C., Dabis, F. and Semaille, C. (2013) Épidémiologie du VIH dans le monde: Particularités de l'épidémie au Nord et au Sud. Virologie, 17, 132-144.

[3] Organisation Mondiale de la Santé (2017) Le VIH/Sida. Aide-mémoire Actualisé. http://www.who.int/mediacentre/factsheets/fs360/fr/

[4] Organisation Mondiale de la Santé (2016) Mettre fin au VIH/Sida d'ici 2030: Cadre d'action dans la région africaine de l'OMS 2016-2020. Bureau régional de L'AFR/ RC66/11, Organisation Mondiale de la Santé, Geneve, 1.

[5] Ministère de la santé publique (2014) Deuxième enquête démographique et de santé (EDS-RDC II 2013-2014), Rapport Final, Democratic Republic of Congo, Kinshasa, 27.

[6] PNLS RDC (2015) Cap vers l'objectif 90-90-90. Rapport Annuel, 15.

[7] Chelli, J., Bellazreg, F., Aouem, A., Hattab, Z., Mesmia, H. and Ben Lasfar, N. (2016) Causes de décès des patients infectés par le VIH dans le centre de Tunisie. The Pan African Médial Journal, 25, Article No. 105. https://doi.org/10.11604/pamj.2016.25.105.9748

[8] Raizada, N., Chauhan, L.S., Khera, A., Sokhey, J., Wares, D.F., Sahu, S., et al. (2008) HIV Seroprevalence among Tuberculosis Patients in India. PLOS ONE, 3, e2970. https://doi.org/10.1371/journal.pone.0002970

[9] Organisation Mondiale de la Santé (2016) Rapport sur la lutte contre la tuberculose dans le monde. Organisation Mondiale de la Santé, Geneve, 1

[10] Organisation Mondiale de la Santé (2014) Stratégie pour mettre fin à la tuberculose d'ici 2035. Rapport de lutte contre la tuberculose, Organisation Mondiale de la Santé, Geneve.

[11] Organisation Mondiale de la Santé (2009) Focus sur la coïnfection VIH/Tuberculose. Rapport de la journée mondiale de la tuberculose 24 mars. Organisation Mondiale de la Santé, Geneve.

[12] Organisation Mondiale de la Santé and Stop TB Partnership (2010) Questions prioritaires de recherche sur la coïnfection tuberculose/VIH dans les pays prévalents pour le VIH et disposant de ressources limitées. Organisation Mondiale de la Santé, Geneva, 3

[13] Joint United Nations Programme on HIV/AIDS and Organisation Mondiale de la Santé (2009) Point sur l'epidemie mondial du sida.

[14] Cain, K.P., Anekthananon, T., Burapat, C., Akksilp, S., Mankhatitham, W., Srinak, C., et al. (2009) Les causes de décès chez les personnes infectées par le VIH qui ont tuberculosis, Thailand. Emerging Infectious Diseases, 15, 258-164. https://doi.org/10.3201/eid1502.080942

[15] Organisation Mondial de la Santé (2010) Global Tuberculosis Control' Rapport. Organisation Mondial de la Santé, Geneve.

[16] World Health Organization (2016) Global Report Tuberculosis. World Health Organization, Geneve, 1.

[17] World Health Organization (2017) Global Report Tuberculosis. World Health Organization, Geneve, 17, 29.

[18] World Health Organization (2015) Global Report Tuberculosis. World Health Organization, Geneve, 27, 96.

[19] Joint United Nations Programme on HIV and AIDS (2017) Estimation ONUSIDA.

[20] PNLT Kongo Central (2016) Rapport Annuel 2011-2016.

[21] World Health Organization (2014) Global Report Tuberculosis. World Health Or- 
ganization, Geneva, 4.

[22] Fujiwara et Coll (2012) Mise en œuvre d'activités conjointes de lutte contre la tuberculose et le VIH: Un guide programmatique. Union Internationale Contre la Tuberculose et les Maladies Respiratoires, Paris, 5.

[23] Fiogbe, A., Adjoh, K.S., Ouedraogo, A.R., Maiga, A.I., Wateba, M.I., Okemba-Okombi, F.H., et al. (2015) Co-Infection VIH/Tuberculose en milieu rural au Benin: Cas De La Zone Sanitaire Djougou-Ouake-Copargo (Nord-Ouest Benin). Mali Medical, Tome XXX, 33.

[24] Organisation Mondiale de la Santé(2016) Rapport sur la lutte contre la tuberculose dans le monde. Organisation Mondiale de la Santé, Geneva, 3.

[25] Soyam, V.C, Das, J., Rajeeva, T.C., Boro, P. and Kohli, C. (2016) Prevalence and Socio-Demographic Correlates of VIH among Tuberculosis Patients of DOTS Centre in Delhi. Asian Journal of Medical Sciences, 7, 53-58. https://doi.org/10.3126/ajms.v7i1.12744

[26] Arun Mohan, M.V., Tejaswi, H.J. and Ranganath, T.S. (2016) Socio-Demographic Profile of TB-HIV Co-Infected Adults and It's Association with Tuberculosis Treatment Outcome, in a South Indian City. International Journal of Community Medicine and Public Health, 3, 2-4.

[27] Nascimento do Prado, T., Miranda, A.E., de Souza, F.M., dos Santos Dias, E., Sousa, L.K.F., Arakaki-Sanchez, D., et al. (2014) Factors Associated with Tuberculosis by HIV Status in the Brazilian National Surveillance System: A Cross Sectional Study. BMC Infectious Diseases, 14, Article No. 415.

https://doi.org/10.1186/1471-2334-14-415

[28] Musafiri, J., Mbayo, P.M., Bakaswa, G., Kaswa, M. and Likwela, J.L. (2013) HIV Seroprevalence among Tuberculosis Patients in Kisangani in the Democratic Republic of Congo. Santé Publique, 25, 483-490. https://doi.org/10.3917/spub.134.0483

[29] Akilimali, P.Z., Tshilumbu, J.M.K., Mavila, A.K. and Kaba, D.K. (2013) Issues thérapeutiques du traitement antituberculeux dans le contexte de la co-infection VIH-tuberculose: Cohorte du centre de Kabinda à Kinshasa, République démocratique du Congo. Revue d Épidémiologie et de Santé Publique, 63, 387-393. https://doi.org/10.1016/j.respe.2015.09.007

[30] Alemu, Y.M., Awoke, W. and Wilder-Smith, A. (2016) Determinants for Tuberculoses in HIV-Infected Adults in Northwest Ethiopia. BMJ Open, 6, Article ID: e009058. https://doi.org/10.1136/bmjopen-2015-009058

[31] Akilimali, P.Z., Mafuta, E.M., Kaba, D.N., Kimpanga, P., Kayembe, N.J.M., Hernandez, J., et al. (2009) Issue thérapeutique des patients tuberculeux suivis dans les centres de santé de diagnostic et de traitement de la Ville de Matadi, dans le contexte du VIH. Annals of African Medicine, 5, 920-925.

[32] Batista, J., de Albuquerque, M., Maruza, M., Ximenes, R., Santos, M., Montarroyos, U.R., et al. (2013) Incidence and Risk Factors for Tuberculosis in People Living with HIV: Cohort from HIV Referral Health Centers in Recife, Brazil. PLoS ONE, 8, e63916.

[33] Yone, É.W.P., Kuaban, C. and Kengne, A.P. (2009) Impact de l'infection à VIH sur l'évolution de la tuberculose chez l'adulte à Yaoundé. Cameroun. Revue de Pneumologie Clinique, 68, 338-344. https://doi.org/10.1016/j.pneumo.2012.10.001

[34] Goluba, J.E., Pronyk, P., Mohapi, L., Thsabangu, N., Moshabela, M., Struthers, H., et al. (2009) Isoniazid Preventive Therapy, HAART and Tuberculosis Risk in HIV-Infected Adults in South Africa: A Prospective Cohort. AIDS, 23, 631-636. 
https://doi.org/10.1097/QAD.0b013e328327964f

[35] Kibret, K.T., Yalew, A.W., Belaineh, B.G. and Asres, M.M. (2013) Determinants Factors Associated with Occurrence of Tuberculosis among Adult People Living with HIV after Antiretroviral Treatment Initiation in Addis Ababa, Ethiopia: A Case Control Study. PLoS ONE, 8, e64488.

https://doi.org/10.1371/journal.pone.0064488

[36] Baromètre Santé (2013) Usages de tabac, d'alcool et de drogues illicites et pratiques de jeu en région Paca. ORS Paca-SESSTIM (UMR 912 Inserm-IRD-Université Aix-Marseille, Marseille

[37] Mbopi-Kéou, F.X., Dempouo Djomassi, L. and Monebenimp, F. (2012) Étude des facteurs liés à l'observance au traitement antiretroviral chez les patients suivis à l'unité de prise en charge du VIH/SIDA de l'hôpital de district de Dschang. Cameroun. The Pan African Medical Journal, 12, Article No. 55.

https://doi.org/10.11604/pamj.2012.12.55.1521

[38] PNLT (2014) Guide PATI 5. PNLT, 19-21.

[39] Magadi, M. and Desta, M. (2011) Multilevel Analysis of Determinants and Cross-National Variations of HIV Seropositivity in Sub-Saharan Africa: Evidence from the DHS. Health \& Place, 17, 1067-1083.

https://doi.org/10.1016/j.healthplace.2011.06.004

[40] Shuper, P.A., Neuman, M., Kanteres, F., Baliunas, D., Joharchi, N. and Rehm, J. (2010) Causal Considerations on Alcohol and HIV/AIDS-A Systematic Review. Alcohol and Alcoholism, 45, 159-166. https://doi.org/10.1093/alcalc/agp091 